\title{
13. The Mismeasure of Nations: A Review Essay on the Human Development Report 1998'
}

\author{
Ian Castles
}

The annual Human Development Report, published for the United Nations Development Program (UNDP) by the Oxford University Press, is promoted by the UNDP as 'the only comprehensive guide to global human development available on the market' (UNDP 1998c). Since the series was launched in 1990, these reports have been extraordinarily influential. According to Amartya Sen, speaking at a memorial meeting for the originator of the series, Mahbub ul Haq, on 15 October 1998, the Human Development Report 'had a profound effect on the way policy makers, public servants and the news media as well as economists and other social scientists view social and economic advancement'. Professor Sen went on to describe the Report as 'one of the major sources of information and understanding of the social and economic world' (Sen 1998).

The release of each Human Development Report has become a significant global event. The 1998 report was launched on 9 September at The Hague City Hall and 'in more than 100 capitals worldwide'. In support of the report's theme of 'Consumption for human development', visitors to the launch and the associated events 'were able to purchase ecologically and socially sound products at a consumer's market; sit in on small workshops and discussion groups on consumption issues; and visit displays on development and the environment by dozens of non-government organizations' (UNDP 1998d).

In all, Human Development Report 1998 was published in ten languages: English, French, German, Italian, Portuguese, Spanish, Catalan, Arabic, Japanese and Russian. The associated Human Development 1998 Database on diskettes facilitates the compilation of tailored reports on the 'demographic, social, economic and environmental issues of human development'. Prospective users are advised to 'simply select one or more of 353 social indicators, select from 174 countries and/or 28 regional aggregates and run with the report'.

With unconscious irony, the 1998 Report refers to the difficulties for local and national producers that arise from 'the opening of consumer markets with a constant flow of new products':

1 Review of United Nations Development Program, Human Development Report 1998. New York: Oxford University Press; This paper was first published in Population and Development Review 24 (4) (December 1998): Reprinted with the permission of the Population Council. Except where otherwise indicated, all figures and tables in this chapter are Castles' own. 
Market research identifies 'global elites' and 'global middle classes' who follow the same consumption styles, showing preferences for 'global brands'. There are the 'global teens' ... inhabiting a 'global space', a single pop-culture world, soaking up the same videos and music and providing a huge market for designer running shoes, $t$-shirts and jeans.

(UNDP 1998a: 6)

This review will argue that the Human Development Report is itself the quintessential 'global brand' of the 1990s, and that its dominant position in the global market for information on the social and economic world owes little to its intrinsic qualities and much to the packaging and promotional efforts of its multinational sponsor.

\section{Statistical misunderstandings and errors}

For every reader of the Human Development Report, there are thousands who read newspaper items purporting to summarise its contents. As few journalists can be expected to read and comprehend a 240-page report, most of the articles are taken from news releases produced in the UNDP's Public Affairs Department.

The role of these news releases is well illustrated by the 'media advisory' for an invitation-only advance briefing on the Human Development Report 1998, which was hosted by the UNDP Administrator at a New York restaurant just one week before the global launch at The Hague. The release was headed 'Despite record-high global consumption, ranks of poor, hungry and homeless are growing in rich nations as well as poor'; and it claimed that 'homelessness and illiteracy in industrialized countries continue to rise, according to the 1998 Human Development Report ...' (UNDP 1998b).

Perhaps no one noticed, but the Report did not say this. All of its claims about poverty and illiteracy in the industrial countries related to the situation at a point in time, not to trends over time. Reference was made to rising levels of malnutrition in Eastern Europe and the Commonwealth of Independent States, but few readers would have thought of these countries as 'rich nations'. The key observation about hunger was unexceptionable if platitudinous: it 'is not as pervasive' in the industrial countries as in the developing countries (UNDP 1998a: 27).

By way of contrast, the key observation about homelessness in the industrial countries was obviously wrong. In the 1997 volume it had been argued that 'the most extreme housing deprivation is to have no home, and worldwide, an estimated 100 million are homeless' (UNDP 1997a:29). In the 1998 Report, however, it was said that 'around 100 million are thought to be homeless' in the developing countries alone and that 'more than 100 million are homeless' in the 
industrial countries (UNDP 1998a: 2, 25, 27). Taken together with population data, these figures imply that the homeless represent only two per cent of the population of the developing countries, but eight per cent of the population of the industrial countries. Clearly one or both of these percentages must be wrong.

There are well-known methodological problems in measuring homelessness, and most studies agree that the number of 'homeless people' at a particular time is not a satisfactory indicator. Alternative approaches have yielded more carefully stated conclusions: for example, 'In New York nearly a quarter of a million people, more than 3 per cent of the city's population, have stayed in a shelter at some point in the past five years' (UNDP 1997a: 29). But the claim in Human Development Report 1998 is that more than 100 million people in the industrial countries are homeless ('a shockingly high number amid the affluence'), not that this number of people have experienced homelessness (UNDP 1998a: 27).

In the same list of bullet points, under the heading 'Measuring human poverty in industrial countries', the 1998 Report asserts that 'Unemployment among youth (age 15-24) has reached staggering heights, with 32 per cent of young women and 22 per cent of young men in France unemployed, 39 and 30 per cent in Italy and 49 and 36 per cent in Spain' (UNDPa: 27). All of these figures are wrong, the correct percentages being far lower than those cited. For 1995 - the reference year in the table from which the figures are drawn - nine per cent of young women and seven per cent of young men in France were unemployed. In Italy the figures were 14 per cent and 12 per cent, and in Spain 18 per cent and 16 per cent.

The errors relating to youth unemployment in this year's Report can be attributed to inadequate documentation in the 'Human Development Indicators' section of the Report itself. In 1998, for the sixth successive year, this section included statistics of the 'youth unemployment rate' in industrial countries (UNDP 1998a: 192); but, as in earlier Reports the compilers failed to mention that the rates relate unemployment to the labor force in the relevant age/sex group, not to the population in that group. As a result, it is likely that many readers of the Reports, and many of the users of the Human Development 1998 Database, will have made the same mistake as this year's authors. The ILO, the OECD and many national statistical offices are striving to remove common misunderstandings about the scale and nature of youth unemployment in the industrial countries that the UNDP is helping to create.

Additional sources of confusion have been introduced in the 1998 Report with the unveiling of 'the new human poverty index (HPI-2)'. According to the authors, this index 'shows conclusively that under-consumption and human deprivation are not just the lot of poor people in the developing world' (UNDP 1998a: 2). 
One element of HPI-2 is a measure identified as 'People not expected to survive to age 60 (\% of total population) 1995' (UNDP 1998a: 28, 186). This indicator does not represent the percentage of those living in 1995 who could not expect to live until the age of 60 , but the percentage of a hypothetical population born in 1995 who would not survive to age 60 if that population were subject at each age to the mortality rates of 1995 .

Again the authors of the Report appear to have misinterpreted their selected indicator. They say that 'Nearly 200 million people [in the industrial countries] are not expected to survive to age 60' (UNDP 1998a: 27), this being the product of the population of the industrial countries (about 1200 million) and the proportion of persons not surviving from age zero to age 60 at 1995 mortality rates (16 per cent). The proportion of persons not surviving from their present age will, of course, be much lower. And the number of people in the industrial countries who are not expected to survive from their present age to age 60 is about 100 million, not 200 million.

In any case, the key point is that mortality rates are decreasing at all ages. During the twentieth century, expected survival rates from birth to age 60 in such countries as Britain and France have increased from about 45 per cent to about 90 per cent (Keyfitz and Flieger 1968: 324, 525; UNDP 1998a: 28, 186). In these countries, the chance of survival from age zero to age 60 is now greater than was the chance of survival from age zero to age one in 1900. Of course, there are still 'millions' who will not survive to age 60 , but it is somewhat perverse to present this as a manifestation of 'human deprivation'.

\section{The Human Development Index: Crude measure or policy guide?}

The First Human Development Report (1990) introduced a new measure of human development. Indicators of life expectancy, educational attainment, and income were combined into a composite 'human development index' (HDI). In his speech at the memorial meeting for Mahbub ul Haq in October, Amartya Sen recalled his initial doubts about trying 'to catch in one simple number a complex reality about human development and deprivation'. But Sen explained that he came to accept Haq's view that the HDI was valuable 'as an instrument of public communication'. This 'deliberately constructed crude measure' was a means of 'getting the ear of the world through the high publicity associated with [its] transparent simplicity ...' (Sen 1998).

But the proponents of HDI saw other benefits in the 'transparent simplicity' of the index. It was argued in the first Report that 'Too many indicators could produce a perplexing picture - perhaps distracting policy makers from the main overall trends'; and that 'Having too many indicators in the index would blur its 
focus and make it difficult to interpret and use' (UNDP 1990: 11, 13). The world was encouraged to believe that this simple device not only enabled 'people and their governments to evaluate progress over time' but also permitted the determination of 'priorities for policy intervention' (UNDP 1994: 91).

Successive reports promoted the UNDP's special new product. In the second Report (1991), it was claimed that the HDI was 'a reliable measure of socioeconomic progress' (UNDP 1991:15). Readers were referred to a technical note in which the 'robustness' of the HDI had been established by statistical tests:

Another way to check the index is to try a different weighting. Suppose we take the product of the three measures and then take the cube rootthat is, the geometric rather than the arithmetic mean. This is the same as the equally weighted sum of the logarithms of all three variables. Taking the log of life expectancy, the log of literacy and the log of income ...and arranging them - gives a new index that also has an extremely high rank correlation with the original HDI ... (UNDP 1991: 88).

The conclusion was that 'the HDI, simple as it is, stands up as a robust device for making intercountry comparisons' (UNDP 1991: 89). In the 1995 Report, readers were assured that 'the HDI has been found to be a robust measure: even when different weights are tried, the country HDI values do not change significantly' (UNDP 1995: 122). Many development economists were less impressed. Allen Kelley argued in this journal that the HDI 'offers only limited insights beyond those obtained by small modifications to simple measures of economic output' (Kelley 1991: 315). And in An Inquiry into Well-being and Destitution, Partha Dasgupta judged the index to be 'not much good; it has too many unappealing properties [and] ... is also excessively partial' (Dasgupta 1993: 107).

There are grounds for believing that the vigorous promotion of the merits of the HDI has encouraged a simplistic approach to public policy and administration in many developing countries. In the 1995 Report, it was said that 'Its rankings [had] opened healthy competition among countries to improve their human development status' - that is, their HDI score (UNDP 1995: 119). and the 1998 Report records that president Fidel Ramos of the Philippines had 'asked the National Statistical Coordination Board to include the human development index regularly in the system of statistics used to track variations across provinces', and had 'directed the Department of Interior and Local Government to closely monitor provincial and municipal human development indices - and to institute rewards for good performance' (UNDP 1998a: 18).

As a 'deliberately constructed crude measure' that was devised as a means of 'getting the ear of the world', the HDI may not be a satisfactory indicator of the performance of provincial administrators. For reasons that will be explained below, it may also be an unsatisfactory tool for monitoring progress and determining priorities for policy intervention. 


\section{The HDI in practice: Country examples}

\section{Madagascar, Mauritius and Tanzania}

From the outset, the creators of the HDI reflected the complex concept of 'human development' as a single number. A country's human development performance was related to its potential by means of a crude comparison of its relative ranking in 'league tables' of HDI rank and GNP per capita. In the HDI table in each Human Development Report, countries were categorised according to whether their 'HDI rank' was above or below their 'GNP rank'.

In this year's Report [1998], two island-countries in the Indian Ocean are featured in the discussion of these relative rankings. Madagascar, which is almost as large as Texas, is one of four low-income countries that are said to 'rank higher on the HDI than on GDP per capita (PPP\$ [purchasing power parity dollars]), suggesting that they have converted economic prosperity into human capabilities very effectively' - an achievement described as 'noteworthy.' Mauritius, 1000 kilometres to the east of Madagascar and smaller than Rhode Island, is one of four 'more affluent' countries whose 'ranking on the HDI is lower than that on GDP per capita (PPP\$), suggesting that they have failed to translate economic prosperity into correspondingly better lives for their people'. This is described as 'particularly disturbing' (UNDP 1998a: 20).

The following table, which is drawn entirely from statistics in the Human Development Report 1998, provides an alternative perspective on the development record of these two countries:

\begin{tabular}{|l|r|r|}
\hline & Madagascar & Mauritius \\
\hline Land area ('000 ha) & 58,154 & 203 \\
\hline Total real GDP (\$PPPbn) & 10 & 15 \\
\hline Real GDP per capita (\$PPP) & 673 & 13,294 \\
\hline Life expectancy at birth (years) & 58 & 71 \\
\hline Under five mortality rate (per 1,000 live births) & 66 & 23 \\
\hline Population without access to safe water (\%) & 62 & 2 \\
\hline Population without access to health services (\%) & 59 & 0 \\
\hline Population without access to sanitation (\%) & 72 & 0 \\
\hline Children not reaching grade five (\%) & 54 & 1 \\
\hline Adult illiteracy rate (\%) & & 17 \\
\hline
\end{tabular}

In 1955, Sir Arthur Lewis identified Mauritius as a country that faced problems in achieving development because its population was 'much too large in relation 
to agriculture, and at the same time much too small to support a wide range of industrial development' (Lewis 1955: 324). Almost 40 years later, another eminent development economist, Partha Dasgupta, pointed out that Mauritius had been placed first in a 'ranking of living standards data of 48 of the world's poorest countries' and commented that 'Her presence at the top of our ranking was a revelation to me' (Dasgupta 1993: 113). Lewis would not have believed it possible that Mauritius would achieve a level of real GDP per head 20 times that of Madagascar.

While Mauritius has succeeded beyond all expectation, Madagascar has continued to disappoint. The country is regarded by the World Bank as having 'enormous potential for growth', with 'abundant and varied natural resources'. But as a result of its failure to turn these resources to advantage, it is now

...among the poorest countries in the world. Poverty has increased and deepened substantially over the past two and a half decades, with real per capita income decreasing 40 percent between 1971 and 1991. The poverty assessment estimates that 70 per cent of the population are poor and 59 per cent are extremely poor (World Bank 1997: 88-90).

It is little short of tragic that the 'team of eminent economists and distinguished development professionals' who prepare the Human Development Report have told the world that poverty stricken Madagascar has turned its 'economic prosperity into human capabilities very effectively'; and that affluent Mauritius has 'failed to translate economic prosperity into correspondingly better lives for [its] people'.

Regrettably, these examples from this year's Report are part of a consistent pattern of misleading commentary on the relative performance of different countries. In the 1995 Report it was claimed that 'A look at the highest positive and negative differences between HDI and real GDP per capita ranks shows clearly that such countries as Costa Rica and Madagascar used their economic growth to enhance the lives of their people' (UNDP 1995: 22). The fact was that Madagascar had had no economic growth to 'use': between 1965 and 1996, its GNP per capita had decreased at an average rate of two per cent per annum (World Bank 1998: 24). But the authors of the Reports had become so enmeshed in the scrutiny of 'positive and negative differences' that they had lost sight of realities that in the absence of the HDI would have been painfully obvious.

The 1996 Report quoted with approval a statement by Julius Nyerere, who had been President of Tanzania for over 30 years: 'Every proposal must be judged by the criterion of whether it serves the purpose of development - and the purpose of development is the people' (UNDP 1996: 46). Notwithstanding their leader's rhetoric, the people of Tanzania are among the very few in the world who are even poorer than those of Madagascar, and their life expectancy at birth is seven 
years shorter. Yet Tanzania is also in the list of four low-income countries who are complimented in this year's Report for their noteworthy achievements in converting their 'economic prosperity into human capabilities very effectively'.

\section{Oman}

In the early Reports, oil-rich Oman was seen as the worst performer in the 'negative difference' stakes. With an HDI rank 56 places below its GNP rank, the first Report (1990) listed it first among a group of countries 'that ...have yet to translate their income into corresponding levels of human development' (UNDP 1990: 16). In the second Report (1991), Oman was included in a group of 'countries whose HDI rank is 20 or more places lower than their per capita income rank, showing that they have considerable potential to improve their human development levels - by spending their incomes better and planning their investment priorities more wisely' (UNDP 1991: 15). And in the third Report (1992), Oman was again singled out for its alleged failure to translate its high income into a commensurate HDI:

...Oman has a per capita income two and a half times that of Costa Rica, but its literacy rate is one-third of Costa Rica's, its average life expectancy is nine years less and its child mortality rate is two and a quarter times higher. All this can be reduced to the information that Oman has an HDI of 0.589, while Costa Rica's HDI is 0.842 - 43\% higher. (UNDP 1992: 20)

The issues of principle that are raised by figuring of this kind will not be pursued here, except to note that they are not disposed of by tests of 'robustness', such as comparisons of results with the cube root of the product of three component measures. But there is also a practical question that has received little attention in the debate over the HDI: the quality of the underlying data.

When the index first appeared in 1990, the estimated expectation of life at birth in Oman in the reference year (1987) was given as 57 years - less than in China, India, Pakistan, Brazil, Thailand, Philippines, Turkey or Iran. It is now estimated that life expectancy in Oman in 1985-90 was in fact 68 years - greater than in all of these countries (United Nations 1998). The charge that Oman had failed to translate its income level into corresponding levels of human development was made on the assumption that the country's average life expectancy was in the lowest quartile of the world's population: we now know that it was in the highest quartile. The original calculations of Oman's 'deprivation' with respect to life expectancy in 1987, on a scale of zero to one, was 0.60 ; on the estimates now available, Oman's 'deprivation,' for the same year and calculated on the same basis, would have been 0.24 . 
The first HDI calculations assumed that the adult literacy rate in Oman in 1985, on the basis of an estimate made by UNDP itself, was 30 per cent. UNESCO has now published an estimate that Oman's adult literacy rate in 1993 was 60 per cent (UNESCO 1998a). This implies that the rate in 1985 was far higher than the 30 per cent which the UNDP estimated in the 1990 and 1991 Reports; and that the country's level of adult literacy in the 1990s has been substantially higher than the figure of 35 per cent that was published in every Human Development Report from 1992 to 1997 (and that went into the calculation that Costa Rica's HDI was 43 per cent greater than Oman's).

The estimates of 'mean years of schooling' were even more astray, and here the errors are inexplicable. The HDI calculations in the 1992 Report put the 'mean years of schooling' in Oman at only 0.9 years, compared with 5.7 years in Costa Rica. These figures were clearly inconsistent with UNESCO data, which showed that Oman had established a system of universal primary education. In fact, the UNESCO Statistical Yearbook 1992 (UNESCO 1993) gave the gross enrolment rates at primary level in 1990 as: Oman, 103 per cent (up from 60 per cent in 1980) and Costa Rica, 102 per cent (down from 105 per cent in 1980). At the secondary level the rates were: Oman, 54 per cent (up from 14 per cent in 1980) and Costa Rica, 42 per cent (down from 48 per cent in 1980).

At the time of the 1992 Human Development Report, Oman's per capita income was two and a half times that of Costa Rica. By 1996, Oman's margin of advantage over Costa Rica had been reduced to one-third (World Bank 1998). It was becoming difficult to suggest that Oman had failed 'to translate [its] income into corresponding levels of human development,' as had been alleged in the 1990 Report. This was not because Oman had suddenly begun 'spending [its] income better and planning [its] investment priorities more wisely', as the authors of the 1991 Report had urged (1991: 15). It was because circumstances beyond its control had diminished the country's income (thereby reducing the 'negative difference' between its HDI and GNP rankings).

The crude technique of cataloguing these positive and negative differences implicitly assumes that a country's progress in enhancing life expectancy and literacy levels can be sensitive to such temporary phenomena as rises and falls in the price of oil. It should always have been obvious that this assumption was invalid, and specifically in the case of Oman the 1997 Report effectively acknowledged that the judgements made in earlier reports had been unsound:

Beginning in 1970, Oman undertook a comprehensive program of human development, achieving some of the most rapid advances ever recorded. Life expectancy has increased by 30 years ... Improvements in education have been even more impressive ... Most health problems associated with poverty and lack of schooling have been controlled or 
eradicated ... Advances in health and education have been accompanied by rapid advances in other areas of human development ... Oil revenues ... made possible such rapid progress and such a high standard of living. But without the commitment to human development, Oman might have been wealthy but unhealthy. Oman has been a global pace-setter in human development. (UNDP 1997a: 28).

Only five years earlier, the originator of the Human Development Report, Mahbub ul Haq, had singled out Oman as the prime example of a country that was 'wealthy but unhealthy':

...beyond the confusing maze of GNP numbers, beyond the curling smoke of industrial chimneys, beyond the endless fascination with budget deficits and balance of payments crises - it is people who matter. Costa Rica has a per capita income only one-third that of Oman but its literacy rate is three times higher, its life expectancy ten years longer, and its people enjoy a wide range of economic, social and political freedoms. (Haq 1992: 1)

\section{Costa Rica}

As this extract exemplifies, Costa Rica has always been seen by the HDI team as the prime example of a country that has become healthy without needing to be wealthy. The 1990 Report listed it first in a table headed 'Top 15 countries in democratic human development' and asserted that 'Costa Rica shows that assigning a high priority to social sector expenditures, coupled with wellstructured across-the-board policies, can dramatically improve the human condition despite only moderate growth and a poor distribution of income' (UNDP 1990: 16, 51). The 1991 Report proclaimed that 'Costa Rica remains an outstanding example of human development in Latin America - and the world' (UNDP 1991: 59). And, as already noted, the 1992 Report put Costa Rica's HDI at 43 per cent higher than Oman's.

In the 1994 Report, Costa Rica was one of seven listed countries whose 'HDI rank is far ahead of their income rank, showing that they have made more judicious use of their income to improve the capabilities of their people' (UNDP 1994: 5). The similar comment on Costa Rica and Madagascar in the 1995 Report has already been cited. Both the 1996 and 1997 Reports singled out Costa Rica and Viet Nam as countries that had 'effectively translated the benefits of economic growth into improvements in the lives of their people'; and the 1996 Report also identified Costa Rica, together with Canada, China and Sri Lanka, as 'countries that convert income into capabilities more effectively than others, countries that constitute the "human development frontier" of efficiency' (UNDP 1996: 31, 67; 1997a: 46). 
This year's Report gives special praise to Costa Rica as 'a global leader in environmental sustainability'. In a box in the chapter 'Agenda for Action', the country's 'coherent package' of environmental protection policies is outlined. These policies appear to rely heavily on public relations activities:

The hundred cleanest companies in Costa Rica are named annually, and a green seal of quality is given to gas stations with the best records in preventing air and water pollution and in treating waste water. A red stamp is for those with the worst records. The government and civil society also apply moral suasion by using ad campaigns to convince people that a healthy environment is good in itself, contributes to human wellbeing and is good for tourism. (UNDP 1998a: 99)

Summaries of Costa Rica's own human development reports (UNDP 1997b), which are the outcome of a project sponsored by a consortium of national and international institutions (including UNDP, the European Union, and the Council of State Universities), take a quite different view of Costa Rica's environmental record. The first report, published in 1995, was critical of the fact that 'the country's economic growth [had] relied heavily on depredation of the country's natural endowment'; that 'agroecological limitations of natural resources have not been taken into account'; and that 'even worse, the nation's developmental goals have been reached, in good part, at the expense of those resources'. With the country's primary forest coverage reduced from 56 per cent of its area in 1960 to 22 per cent in 1990, the report warned that 'If this pace continues, Costa Rica will exhaust its primary forests within eight years...'

Comments in other sections of this report, and in a second report published in 1996, did not support the glowing views of Costa Rica's human development performance espoused in successive Human Development Reports. The country reports pointed out that 'one in five children between 5 and 11 works and $78 \%$ of the youth [labor force] have only an incomplete primary education'; that 62 per cent of all heads of households did not finish primary school; that 'nearly $25 \%$ of adolescents between 12 and 17 years old work with almost no job skills'; that 'children and adolescents watch TV an average of 6.7 hours per day, while receiving less than 5 hours of school'; and that 'In spite of governmental public relations campaigns, the majority of the people thought that the current administration's performance was 'bad' or 'very bad' (UNDP 1997b).

Remarkably, the Human Development Reports for the UNDP have not drawn upon these comments in Costa Rica's own human development reports. In this year's Report for example, no mention is made of the finding that Costa Rican children spend far more time watching television than in school, although this was highly relevant to a section of the Report headed 'Information imbalances', which referred to findings that children in Japan and the United States spent almost as much time watching television as in school (UNDP 1998a: 64). As 
'one of the major sources of information and understanding of the social and economic world' (to use Amartya Sen's phrase), one might expect the Human Development Report to provide the same details about information imbalances in the 'outstanding example of human development in Latin America' as it does for countries such as Japan and the United States.

\section{Korea}

This year's Report includes a chart headed 'Similar HDI, different income', which shows graphically that the HDIs of Costa Rica and the Republic of Korea are virtually the same, while Korea's real GDP per capita is almost twice as great. According to the explanatory text, the chart shows that 'The link between economic prosperity and human development is ... neither automatic nor obvious' (UNDP 1998a: 20). As in earlier Reports, the authors have reified the abstract concepts 'economic prosperity' and 'human development' as GDP and HDI numbers and have thereby assumed that the link between HDI and human development (unlike the link between GDP and human development) is automatic and obvious. In fact, the view that Korea and Costa Rica are at a similar level of human development would not be entertained, but for the fact that the near-identity of their HDIs gives it a superficial plausibility.

Between 1965 and 1996, Korea's average rate of growth of GNP per capita was 7.3 per cent per annum, the fastest rate of growth that has ever been achieved by a major economy over a 30 year period. As Costa Rica's per capita GNP growth rate over the same period was a very modest 1.2 per cent per annum (World Bank 1998), it appears that Korea's level of real per capita income increased between the mid-1960s and the mid 1990s from less than one-third to almost double that of Costa Rica.

Because the HDI calculations 'reflect the diminishing returns to transforming income into human capabilities' (UNDP 1990: 12), Korea's much higher per capita income raises its HDI by only 0.009 relative to that of Costa Rica. There are several reasons why a near-doubling in income would have a much larger impact on enlarging people's choices than this small difference in the HDI implies. Perhaps the most important is that the concomitant decrease in the amount of time that people need to spend in order to earn any given level of income provides them with the opportunity to choose more leisure, an aspect of human welfare that is not taken into account in the HDI. According to estimates prepared by Andrew Harvey for the United Nations (United Nations 1995), Koreans - both women and men - devote less time to work and household chores, and have more 'free time', than their counterparts in more than 20 other countries for which statistics are available (including all of the main industrial countries). 
The rate of development in the educational attainment of Korea's adult population has been without precedent for a major country. Between 1960 and 1990, the average total years at schools and higher institutions of the population aged 15 and older increased from 4.25 years to 9.94 years. As a proportion of the average for the OECD countries, average years at school of the population aged 15 and older rose from 60 per cent to 110 per cent. The proportion of Korea's population aged 15 and older who had been at secondary school or higher rose from 20 per cent in 1960 (compared with 38 percent for the OECD total) to 76 percent in 1990 (compared with 63 per cent for the OECD) (Barro and Lee 1993). As noted above, the proportion in Costa Rica was far lower (UNDP 1997b). The much higher level of educational attainment in Korea than in Costa Rica is disregarded in the HDI, except to the extent that it is reflected in a fractionally higher level of adult literacy.

According to UNESCO estimates (1998b), average length of schooling in Korea had reached 14.5 years in 1995, which was higher than in Sweden (14.3 years) and Switzerland (14.0 years). Average length of schooling in Costa Rica was 10.3 years in 1995, which was lower than in all OECD countries except Turkey and also lower than in many other countries of Central and South America including Peru (12.4 years), Chile (11.8 years), Cuba (11.3 years), Dominican Republic (11.2 years), Brazil (11.1 years), Jamaica (11.0 years) Trinidad and Tobago (10.8 years), Venezuela (10.5 years), and Colombia (10.5 years). The far higher level of average time in school in Korea vis-a-vis Costa Rica is not fully reflected in the 'gross enrolment ratios' component of their respective HDIs.

The only element of the HDI in which Costa Rica ranks higher than Korea is 'life expectancy at birth' which is five years greater in Costa Rica. This has a huge impact on the relationship between the HDIs of the two countries (0.027). But the infant mortality rate, which is disregarded in the HDI because it 'is almost perfectly correlated with life expectancy' (UNDP 1995: 121), is far lower in Korea (six infant deaths per thousand births, compared with 13 per thousand in Costa Rica).

\section{Conclusion}

The review of the HDI by Allen Kelley, published in this journal ${ }^{2}$ in 1991 and cited earlier, was entitled "The Human Development Index: 'Handle with care'" (Kelley 1991). Eight more Human Development Reports and eight more HDI 'league tables' have demonstrated the need for even greater care in handling the index - and more circumspection by the UNDP in promoting the usefulness of its product.

2 Population Development Review. 


\section{References}

Barro, Robert J and Jong-Wha Lee (1993). 'International comparisons of eductional attainment', Journal of Monetary Economics 32, no. 3: 363-394.

Dasgupta, Partha (1993). An Inquiry into Well-being and Destitution. Oxford: Clarendon Press.

Haq, Mahbub ul (1992). Human Development in a Changing World. UNDP Occasional Paper 1. New York.

Kelley, Allen C (1991). 'The Human Development Index: 'Handle with care,"' Population and Development Review 17, no. 2:315-324.

Keyfitz, Nathan and Wilhelm Fleiger (1968). World Population. Chicago and London: University of Chicago Press.

Lewis, W Arthur (1955). The Theory of Economic Growth. London. George Allen and Unwin.

OECD (1997). Education at a Glance: OECD Indicators. Paris.

(1998). Quarterly Labour Force Statistics Number 2. Paris.

Sen, Amartya (1998). 'Mahbub ul Haq: the courage and creativity of his ideas', speech at the Memorial Meeting for Mahbub ul Haq, 15 October. UNDP website.

UNDP (1990). Human Development Report. New York: Oxford University Press. (1991). Human Development Report. New York: Oxford University Press. (1992). Human Development Report: New York: Oxford University Press (1993). Human Development Report: New York: Oxford University Press (1994). Human Development Report: New York: Oxford University Press (1995). Human Development Report: New York: Oxford University Press (1996). Human Development Report: New York: Oxford University Press (1997a). Human Development Report: New York: Oxford University Press (1997b). 'Indicators and democratic governance: Measuring sustainable human development in Costa Rica'. UNDP website.

(1998a). Human Development Report. New York: Oxford University Press 
13. The Mismeasure of Nations: A Review Essay on the Human Development Report 1998

(1998b). Media Advisory. 'Invitation-only press luncheon on 2 September to preview UNDP's 1998 Human Development Report', UNDP website.

(1998c). 'About the Human Development Reports', UNDP website. website.

(1998d). 'Human Development Report: News and Events', UNDP

UNESCO (1993). Statistical Yearbook 1992. Paris.

(1998a). Statistical Yearbook 1997. Paris.

(1998b). World Education Report 1998. Oxford: UNESCO Publishing.

United Nations (1995). Statistics and Indicators on the World's Women. New York.

(1997). The Sex and Age Distribution of the World Populations: The 1996 Revision. New York.

(1998). World Population Prospects: The 1996 Revision. New York.

World Bank (1997). Poverty Reduction and The World Bank: Progress in Fiscal 1996and 1997. Washington DC.

(1998). World Development Indicators 1998. Washington, DC. 